\title{
Study on the engineering knowledge in the curriculum instruction of mechanical manufacturing
}

\author{
Zhao Gang ${ }^{1, a^{*}}$, Tao Ping ${ }^{1, b}$ and Zhang Xiang ${ }^{1, c}$
}

1. College of Machinery and Automation, Wuhan University of Science and Technology,

\author{
Wuhan Hubei 430081, China \\ a snowcampus@163.com \\ b taopin_88@163.com \\ c a280472981@163.com
}

Keywords: Mechanical manufacturing; Engineering knowledge; Instruction approach; Theory of constructivism

\begin{abstract}
Engineering knowledge is defined as the knowledge that involves the principles and rules as well as the skills and abilities applied in engineering project. Learning the engineering knowledge is crucial to elevating the undergraduate students' professional capacity. Directed by the theory of constructivism, students' engineering knowledge is integrated continuously according to the complexity, comprehensiveness and scenario features of the engineering knowledge. By strengthening the case study and the practical experience on engineering project, this instruction approach employed in the curriculum of mechanical manufacturing achieves an impressive success for students to learn the engineering knowledge and consequently construct the corresponding knowledge system.
\end{abstract}

\section{Introduction}

"Mechanical Manufacturing" course is not only a professional basic subject, but also an important course in the training system for students whose major is in mechanical engineering. The educational contents include manufacturing theories and methods for various common parts. Through this teaching course, students can grasp the specific methods about manufacturing and calculating of common mechanical parts. The more important thing is to enable students to learn how to analyze and solve the complex problems in practical mechanical engineering applying this course and the course learned before rationally. Besides, students' basic mechanical manufacturing skills are trained through the process. The course plays a role of connecting in the whole teaching system. It not only embodies the comprehensive application of some completed basic subjects, but also lays the foundation for subsequent courses which are related to learning and future technical works. It is the main courses which train students' ability in learning mechanical engineering. In the Mechanical Manufacturing curriculum, there are a lot of scientific theories included such as mathematics, physics, mechanics, etc. Moreover, it also contains a lot of engineering knowledge about mechanical engineering techniques, methods, and engineering experience. This engineering knowledge is very important for students in capabilities cultivation. 


\section{Engineering knowledge and its characters}

Engineering knowledge is the knowledge about engineering theories and rules, skills and abilities. It comes from practice and is vital for engineering ability cultivating. It presents the following features: 1) Highly integration: Due to the subject integrating, profession integrating, science and technology integrating in engineering, the engineering knowledge is highly integrated under the engineering background. It synthesizes natural science, technologies, humanities, social science and a variety of knowledge. The related experience, the special knowledge and experience from its own specificity and regionalism are integrated as well. In addition, They are organically combined and transformed to be plans, methods, processes, procedures, rules, norms and directions which are feasible, dependable, operable and consistent with the practical engineering[1]. 2) Varieties: It contains text-based form and is presented by formulas and graphs. For example, the manufacturing of gears not only has literal description about manufacturing standards, but also has the intensity calculating formulas and graphs about all kinds of parameters for referring. 3) A lot of regions are involved: Account of technical methods and experience of engineering are involved apart from a great deal of theoretical science knowledge. 4) Showing the relevance and progress within the specific discipline: The knowledge among each disciplines and the connection between former and later courses are integrated and related to be a knowledge system of the subject by logical and causal relationship [2]. 5) Practice: Engineering knowledge comes from engineering activities. It is an index of engineering with a strong engineering background. In other words, it has a significant situation, which will lose the structure and meaning of engineering knowledge separating from the engineering context. These various characteristics of engineering knowledge determine the complexity of engineering knowledge which belongs to the field of non-benign. Their learning process is not simple. We need a particular theory as a guidance to explore the learning methods of engineering knowledge.

\section{Study on the engineering knowledge in the curriculum instruction of mechanical manufacturing}

Theoretical fundamentals for learning the engineering knowledge. The learning theory is a branch of pedagogy and psychology in education. The major research is in the nature, mechanisms, motivations, methods and strategies of study. The study of engineering knowledge needs corresponding theory as guidance. The Constructivist Learning Theory regards learning as a process of constructing an individual previous knowledge which is based on the knowledge coming from former courses and experience by the interaction of practical activities and objects. In other words, knowledge is constructed by the learner themselves and learning is the construction of knowledge. The Constructivist Learning Theory is suitable for learning complex knowledge in non-benign field. The Constructivist Learning Theory is obviously fit for knowledge learning result from the complex, comprehensive and situational study. Besides, it offers a scientific engineering direction for engineering knowledge learning.

Constructing steps for engineering knowledge in the curriculum instruction. While learning the "Machine Manufacturing" course, there is a lot of professional knowledge related to mechanical engineering such as the machining and processing planning for various mechanical parts, machines and tools design and manufacturing, and related manufacturing specifications and standards, etc. Each of this unique engineering knowledge has its own advantages. However, there are common features as well. For example, it is very comprehensive, related to various fields, involving a wide range of prominent engineering background and performing in diverse forms, etc. Therefore, it is an 
associated, progressive and gradual sublimation process on learning engineering knowledge for students based on the Constructivist Learning Theory [3]. Association refers to the learning process in engineering knowledge that is associated with other related knowledge and engineering background frequently. Gradual refers to the construction of engineering knowledge that can't be completed at the first trial. In other words, it is a gradual and progressive process. The first step of the gradual process is a low-level construction, and then the second step is to make it deeper with the continuous associating and integrating of knowledge. The last step is applying the engineering knowledge in engineering projects with the application of engineering knowledge integrated with engineering background constantly so that the high-level progressive can be achieved. The founding of engineering knowledge is a progressive process as well. The ultimate goal of this process is to realize the migration to engineering capabilities. Apart from the migration process, the construction of engineering knowledge is a failure [4].

\section{Learning methods for the engineering knowledge in the curriculum instruction.}

In teaching "mechanical manufacturing" course, educators should constantly integrate knowledge, stress case prominent teaching and enhance engineering practice to establish engineering knowledge fluently.

Learning methods based on the knowledge integration. Since the engineering knowledge is extremely comprehensive, other related knowledge are usually used while studying, thus related knowledge should be associated constantly, which is called "knowledge integrating". First of all, it is "lateral knowledge integration" which represents knowledge integration between subjects. "Mechanical Manufacturing" subject connects all the subjects within the whole course system. Related preparatory courses are "Draft Drawing", "Mechanical Design", "Theoretical Mechanics", "Mechanics of Materials", "Engineering Materials", "Fundamental of mechanical manufacturing", "Metal Technology", "Probability and Statistics" and etc. The learned knowledge must be applied in current engineering knowledge learning. While studying the engineering knowledge, related knowledge must be fully integrated to enhance understanding and overall grasp. For instance, when studying the manufacturing knowledge of threading, not only threaded connection specification painting in "Draft Drawing" must be associated, but also knowledge of tools, combined deformation, complex stress state and material performance in "Engineering Materials". While learning the general processes for machining gears, the knowledge of generation method involved in "Mechanical Design" course can be integrated while learning the process planning for gear machining. Engineering knowledge contents a lot of knowledge and fragments in the "Mechanical Design" course [5]. There is no logical connection between the forms and content of every chapter. If every chapter is not related to others and describe its own opinion, it will present a distribution of knowledge like a lonely island which will affect the learning of engineering knowledge. In fact, the manufacturing ideas, manufacturing norms and analysis methods of any general machine parts or unique machine parts are similar. They have common rules to follow. While studying, every related chapters of the course can be integrated based on these common rules and methods. In other words, it is longitudinal integration of knowledge. For example, gears and worms drive has many types the of failure modes in common. The manufacturing technique is analyzed the working condition and force, and find out the main form of invalid, set up relative manufacturing rules. Producing according to the manufacturing norms, state relatively, and analyze its inner source and differences, that would benefit the students greatly. In respect of the concept of the part face, it will appear at the working of many parts in several chapters like threaded connection, key links, belt drive, and so on. During the 
teaching process, students can better grasp the general norms and methods about mechanical parts manufacturing and know how to digest and reflect by fully integrate knowledge in each chapter.

The case study on engineering project for the curriculum instruction. Engineering knowledge comes from engineering activities and has a strong engineering background so that the study of it needs the support of related engineering background. While the teaching of Mechanical Manufacturing, engineering cases should be applied to help students learn it efficiently. Engineering cases teaching is based on the study objects [6].

Engineering case teaching and traditional teaching are greatly different in teaching aims, teaching methods, communication in study, and so on. In respect with teaching aims, engineering case teaching raise up questions through engineering cases [7]. It solves problems on the basis of students, and stress foster students' abilities of analyzing and solving engineering problems. About the text book, engineering case teaching adopt objective descriptive cases for real project situations, it emphasizes engineering background. In teaching method, case teaching stresses inspiration. It is student-centered, teacher-guided, and mainly adopt discuss, analyze, etc. Thus the students and the teachers can exchange professional ideas fluently in various ways.

There includes a great deal of engineering knowledge introduction and study in mechanical design subjects, such as material selection, manufacturing standards, processing customs, and so on [8]. These engineering knowledge are abstractions of the real engineering activities and objects, they are intimate to mechanical background. Therefore, the learning of engineering knowledge is a process integrated continuously under certain engineering background. It will lost the construction and meaning separated from the situation.

The models of engineering case teaching can be diverse. Considering the fact of college education, put engineering case education as class service. That is to say while teaching in class, engineering case education can help students to understand and grasp the theories, also can analyze real problems via old knowledge, and reflect more. As class time is limited, engineering case teaching can't take up the whole class. It's appropriate to adopt class and outclass method to have engineering case teaching. It is to elicit cases in class and require students to analyze engineering cases outclass, then discuss the cases back in class. For example, at the purpose of effectively realize the learning of relative engineering knowledge about each general mechanical components, take automatic packaging machines as a case study. That packaging equipment includes reducer, belt drive, gear mechanism, and the cam mechanism, etc. It also includes general parts shafts, bearings, gears, worm, worm clutch, and so on. It is a kind of mechanical equipment which centered on mechanical transmission while electrical control as an aid. Students should analyze various components function, material performances and processing plans, and so on. In each engineering case teaching, first of all, raise up case analyze requirements according to the teaching aims. Students should work in groups and analyze the processing sequences, design and manufacture the clamps for the key processes in demonstration center out of class. And accomplish case analyze, afterwards write several case reports. Meanwhile, the teacher should give certain guides outclass, and then back to class to discuss, analyze and summarize the case, also write effective evaluation. On the basis of the evaluation, teaching can be perfect about the engineering case.

\section{Conclusion}

Based on the practicality of engineering knowledge, practices like experiments, course designs are included in study. While these practices are far enough, comprehensive innovative practice platform 
such as improve teaching method constantly, establish opening experiments, intern in corporate and engineering innovation design competition and so on, all are much beneficial to promoting engineering knowledge learning [9]. Through large amount of practices to understand and apply the engineering knowledge, students can finally effectively transfer engineering knowledge to engineering capability.

\section{Acknowledgement}

This paper presents the initial achievements of the Teaching Research Project of Hubei Province in 2014, Research on Cultivation Approaches for Students' Capability of Knowledge Construction and the Teaching Practices (Grant No. 2014229).

\section{References}

[1]Deng Bo. Discussion about scientific knowledge-Technical and Engineering knowledge, J. Dialectics of Nature, 2007(10) :51-57.

[2]Fengchun Xie. Research on constructivism and the engineering foundation theory teaching, J. Higher Engineering Education Research, 2010 (4) :151-155.

[3]Hanbing Kong. Engineering disciplines of knowledge evolution and transformation, J. Higher Engineering Education Research, 2011(4):27-34.

[4]Sibao Fu. The project teaching method under the guidance of constructivism learning theory, J. Chinese University Teaching, 2011(2):56-58.

[5]Hegen Xiong. "Mechanical design" teaching method based on knowledge fusion research [J]. Journal of China University Teaching, 2012(12):58-59.

[6]Huarong Wang. In the practice of case teaching to promote university classroom teaching model reform and exploration, J. Journal of China University Teaching, 2011(4) :62-64.

[7]Ping Tao. Engineering application of case teaching in mechanical course, J. China Metallurgical Education, 2013(6): 91-93.

[8]Rong An, Mei Wang. The engineering case teaching based on problem solving, J. A study in the Journal of Higher Engineering Education, 2007(1): 80-82.

[9] Gang Zhao, Liangxi Xie, Gongfa Li. Making the higher education different from what happened in the last decade: A strategic vision of innovation and internationalization. Advances in Education Research. Mar. 2014; 52 (4): 318-324. 